\title{
CABG Surgery Remains the best Option for Patients with Left Main Coronary Disease in Comparison with PCI-DES: Meta-Analysis of Randomized Controlled Trials
}

Michel Pompeu Barros Oliveira Sá1,2,3, MD, MSc, PhD; Artur Freire Soares ${ }^{1,2}$, MD; Rodrigo Gusmão Albuquerque Miranda1,2, MD; Mayara Lopes Araújo 1,2, MD; Alexandre Motta Menezes ${ }^{1,2}$, MD; Frederico Pires Vasconcelos Silva 1,2, MD; Ricardo Carvalho Lima1,2,3, MD, MSc, PhD, ChM

DOI: 10.21470/1678-9741-2017-0081

\section{Abstract}

Objective: To compare the safety and efficacy of coronary artery bypass grafting (CABG) with percutaneous coronary intervention $(\mathrm{PCl})$ using drug-eluting stents (DES) in patients with unprotected left main coronary artery (ULMCA) disease.

Methods: MEDLINE, EMBASE, CENTRAL/CCTR, SciELO, LILACS, Google Scholar and reference lists of relevant articles were searched for clinical studies that reported outcomes at 1-year follow-up after PCI with DES and CABG for the treatment of ULMCA stenosis. Five studies fulfilled our eligibility criteria and they included a total of 4.595 patients (2.298 for CABG and 2.297 for PCI with DES).

Results: At 1-year follow-up, there was no significant difference between CABG and DES groups concerning the risk for death (risk ratio [RR] $0.973, P=0.830$ ), myocardial infarction (RR $0.694, P=0.148$ ), stroke (RR 1.224, $P=0.598)$, and major adverse cerebrovascular and cardiovascular events (RR $0.948, P=0.680$ ). The risk for target vessel revascularization (TVR) was significantly lower in the CABG group compared to the DES group (RR $0.583, P<0.001$ ). It was observed no publication bias regarding the outcomes, but only the outcome TVR was free from substantial statistical heterogeneity of the effects. In the meta-regression, there was evidence that the factor "female gender" modulated the effect regarding myocardial infarction rates, favoring the CABG strategy.

Conclusion: CABG surgery remains the best option of treatment for patients with ULMCA disease, with lower TVR rates.

Keywords: Meta-Analysis. Drug-Eluting Stents. Coronary Artery Bypass. Stents. Percutaneous Coronary Intervention.

\begin{tabular}{|c|c|c|c|}
\hline \multicolumn{4}{|c|}{ Abbreviations, acronyms \& symbols } \\
\hline BMS & $=$ Bare-metal stent & MeSH & $=$ Medical Subject Heading \\
\hline CABG & $=$ Coronary artery bypass grafting & MI & = Myocardial infarction \\
\hline CENTRAL/CCTR & $=$ Cochrane Central Register of Controlled Trials & NR & $=$ Non-reported \\
\hline $\mathrm{Cl}$ & $=$ Confidence interval & OR & $=$ Odds ratio \\
\hline CK-MB & $=$ Creatine kinase-MB & $\mathrm{PCl}$ & $=$ Percutaneous coronary intervention \\
\hline DS & $=$ Diameter stenosis & PCI-DES & $=$ Percutaneous coronary intervention/Drug-eluting stent \\
\hline FFR & $=$ Fractional flow reserve & PICOS & = Population, Intervention, Comparison, Outcome \\
\hline HR & $=$ Hazard ratio & & and Study Design \\
\hline $\begin{array}{l}\text { IVUS MLA } \\
\text { JACC }\end{array}$ & $\begin{array}{l}=\text { Intravascular ultrasound minimal lumen area } \\
=\text { Journal of the American College of Cardiology }\end{array}$ & PRISMA & $\begin{array}{l}=\text { Preferred Reporting Items for Systematic Reviews } \\
\text { and Meta-Analyses }\end{array}$ \\
\hline LAD & $=$ Left anterior descending & RCTs & $=$ Randomized controlled trials \\
\hline LCX & $=$ Left circumflex artery & $\mathbf{R R}$ & $=$ Risk ratio \\
\hline LILACS & $\begin{array}{l}=\text { Latin American and Caribbean Health Sciences } \\
\text { Literature }\end{array}$ & $\begin{array}{l}\text { SciELO } \\
\text { SD }\end{array}$ & $\begin{array}{l}=\text { Scientific Electronic Library Online } \\
=\text { Standard deviation }\end{array}$ \\
\hline LM & $=$ Left main & SE & $=$ Standard error \\
\hline MACCE & $\begin{array}{l}=\text { Major adverse cerebrovascular and } \\
\text { cardiovascular events }\end{array}$ & $\begin{array}{l}\text { TVR } \\
\text { ULMCA }\end{array}$ & $\begin{array}{l}=\text { Target vessel revascularization } \\
=\text { Unprotected left main coronary artery }\end{array}$ \\
\hline
\end{tabular}

'Division of Cardiovascular Surgery, Pronto-Socorro Cardiológico de Pernambuco (PROCAPE), Recife, PE, Brazil.

2Universidade de Pernambuco (UPE), Recife, PE, Brazil.

${ }^{3}$ Nucleus of Postgraduate and Research in Health Sciences of Faculdade de Ciências Médicas de Pernambuco/Instituto de Ciências Biológicas (FCM/ICB), Recife, PE, Brazil.

This study was carried out at the Division of Cardiovascular Surgery, Pronto-Socorro Cardiológico de Pernambuco (PROCAPE), Recife, PE, Brazil.

No financial support.
No conflict of interest.

Correspondence Address:

Michel Pompeu Barros Oliveira Sá

Pronto-Socorro Cardiológico de Pernambuco (PROCAPE)

Rua dos Palmares S/N - Santo Amaro - Recife, PE, Brazil - Zip code: 74970-240

E-mail: michel_pompeu@yahoo.com.br 


\section{INTRODUCTION}

\section{Rationale}

The current international revascularization guidelines recommend revascularization of unprotected left main coronary artery (ULMCA) with coronary artery bypass grafting (CABG) or percutaneous coronary intervention $(\mathrm{PCl})$ in subjects with low (<23: class I, recommendation for CABG or PCI - level of evidence B) and intermediate (23-32: class I for CABG and class Ila for PCI - level of evidence B) SYNTAX scores. The same guidelines recommend against revascularization with $P C I$ of ULMCA disease with high SYNTAX scores ( $\geq 33$ : class I for CABG and class III for PCI - level of evidence B) ${ }^{[1]}$. Capodanno et al. ${ }^{[2]}$ published a metaanalysis of randomized controlled trials (RCTs) and suggested, boldly, that "based on their study, revision of the guidelines regarding left main $\mathrm{PCl}$ is warranted, raising the level of evidence of current recommendations from B to A". Although some RCTs have suggested that $\mathrm{PCI}$ with drug-eluting stent (DES) could be a non-inferior strategy which might be used safely ${ }^{[3,4]}$, sample sizes were not so large (and some conclusions may have been affected by this factor). Recently, the trials EXCEL ${ }^{[5]}$ and NOBLE[ ${ }^{[6]}$ were published, which led us to revisit the literature and carry out a new meta-analysis.

\section{Objective}

We performed a meta-analysis of RCTs to compare CABG to $\mathrm{PCI}$ with DES for the treatment of patients with ULMCA disease, according to the Preferred Reporting Items for Systematic Reviews and Meta-Analyses (PRISMA) statement ${ }^{[7]}$.

\section{METHODS}

\section{Eligibility Criteria}

Using Population, Intervention, Comparison, Outcome and Study Design (PICOS) strategy, studies were considered eligible if: (1) the population comprised patients with ULMCA disease; (2) there was compared efficacy between CABG and PCI with DES; (3) the studied outcomes have included death, myocardial infarction (MI), stroke, target vessel revascularization (TVR) or major adverse cerebrovascular and cardiovascular events (MACCE); (4) there was a follow-up of at least 12 months. There was no restriction on language.

\section{Information Sources}

The following databases were used (until December 2016): MEDLINE, EMBASE, Cochrane Central Register of Controlled Trials (CENTRAL/CCTR), ClinicalTrials.gov, Scientific Electronic Library Online (SciELO), Latin American and Caribbean Health Sciences Literature (LILACS), Google Scholar, and reference lists of relevant articles.

\section{Search}

We conducted the search using Medical Subject Heading (MeSH) terms: ["coronary artery bypass graft" OR "coronary artery bypass grafting" OR "coronary artery bypass surgery"OR "coronary bypass surgery" OR "coronary artery bypass graft surgery" OR "coronary artery bypass" OR "coronary bypass"] AND ["drugeluting stent" OR "sirolimus-eluting stent" OR "paclitaxel-eluting stent" OR "everolimus-eluting stent" OR "biolimus-eluting stent"] AND ["unprotected left main" OR "left main stenting" OR "left main coronary artery disease" OR "left main PCl" OR "unprotected left main coronary artery" OR "left main stenosis" OR "left main coronary artery stenting" OR "unprotected left main stenting"].

\section{Study Selection}

The following steps were taken: (1) identification of titles of records through database searching; (2) removal of duplicates; (3) screening and selection of abstracts; (4) assessment for eligibility through full-text articles; (5) final inclusion in the study.

One reviewer followed the steps 1 to 3. Two independent reviewers followed the step 4 and selected studies. Inclusion or exclusion of studies was decided unanimously. When there was disagreement, a third reviewer took the final decision.

\section{Data Items}

The primary endpoint was the risk ratio (RR) for mortality after PCl-DES or CABG, up to 12 months. Secondary endpoints were the RR for MI, stroke, TVR after the procedure, and MACCE (composite endpoint of death, MI, stroke or TVR).

\section{Data Collection Process}

Two independent reviewers extracted the data. When there was disagreement about it, a third reviewer (the first author) checked the data and made the final decision. From each study, we extracted patients' characteristics, study design, and outcomes at 1 year after treatment of ULMCA stenosis. Alternatively, probabilities of mortality or MACCE were estimated from published Kaplan-Meier survival curves. When it was possible, we also extracted TVR from the total MACCE events and reported this outcome as a separate measure. When MACCE had not been reported, we calculated it using the events of death, $\mathrm{MI}$, stroke and TVR, and reported this outcome as a separate measure.

\section{Risk of Bias in Individual Studies}

Included studies were assessed for the following characteristics: sequence generation (randomization); allocation concealment (selection bias); blinding of participants and personnel (performance bias); blinding of outcome assessors (detection bias) and incomplete outcome data addressed (attrition bias) ${ }^{[8]}$.

Taking these characteristics into account, the papers were classified in A (low risk of bias), B (moderate risk of bias), C (high risk of bias) or D (unclear). Two independent reviewers evaluated the risk of bias. Agreement between the two reviewers was assessed with Kappa statistics for full-text screening and rating of relevance and risk of bias. When there was disagreement about risk of bias, a third reviewer checked the data and made the final decision.

\section{Summary Measures}

The principal summary measures were RRs with 95\% confidence interval $(\mathrm{Cl})$ and $P$ values (statistically significant 
when <0.05). The meta-analysis was completed using the software Comprehensive Meta-Analysis version 2 (Biostat Inc., Englewood, NJ, USA).

\section{Synthesis of Results}

Forest plots were generated for graphical presentations for clinical outcomes and we have performed the I-squared test and Chi statistics for assessment of heterogeneity across the studies ${ }^{[9]}$. Each study was summarized by the RR for PCI-DES compared to CABG. The RRs were combined across studies using DerSimonian-Laird random effects mode ${ }^{[10]}$, weighted by number of events in each study.

\section{Risk of Bias Across Studies}

To assess publication bias, a funnel plot was generated (for each outcome), being statistically evaluated by Begg and Mazumdar's test ${ }^{[11]}$ and Egger's test ${ }^{[12]}$.

\section{Sensitivity Analysis}

We investigated the influence of a single study on the overall effect - by sequentially removing one study - to test the robustness of the main results, so we could verify whether any study had an excessive influence on the overall results or not.

\section{Meta-regression Analysis}

Meta-regression analyses were performed to determine if the effects of CABG were modulated by pre-specified factors. Meta-regression graphs describe the effect of CABG on the outcome (plotted as a log RR on the $y$-axis) as a function of a given factor (plotted as a mean or proportion of that factor on the $x$-axis). Meta-regression coefficients show the estimated increase in log RR per unit increase in the covariate. Since log $R R>0$ corresponds to $R R>1$ and log $R R<0$ corresponds to $R R$ $<1$, a negative coefficient will indicate that when a given factor increases, the OR decreases.

The predetermined modulating factors to be examined were: age (mean), female gender (\%), diabetes (\%), smoke (\%), hypertension (\%), SYNTAX score (mean) and distal left main lesion (\%). This choice was made based on the factors that could recognizably modulate the summary measures when it comes to ULMCA disease. For studies reporting interquartile ranges, the mean was estimated according to the formula [minimum+maximum +2 (median)]/4 and the standard deviation (SD) was calculated based on the formula (maximum-minimum)/6[13].

\section{RESULTS}

\section{Study Selection}

A total of 14.885 citations were identified, of which 32 studies seemed to be potentially relevant and were retrieved as full-texts. Five publications fulfilled our eligibility criteria ${ }^{[3-6,14]}$. Interobserver reliability of study relevance was excellent (Kappa $=0.83$ ). Agreement for decisions related to study validity was very good (Kappa $=0.80)$. The search strategy can be seen in Figure 1.

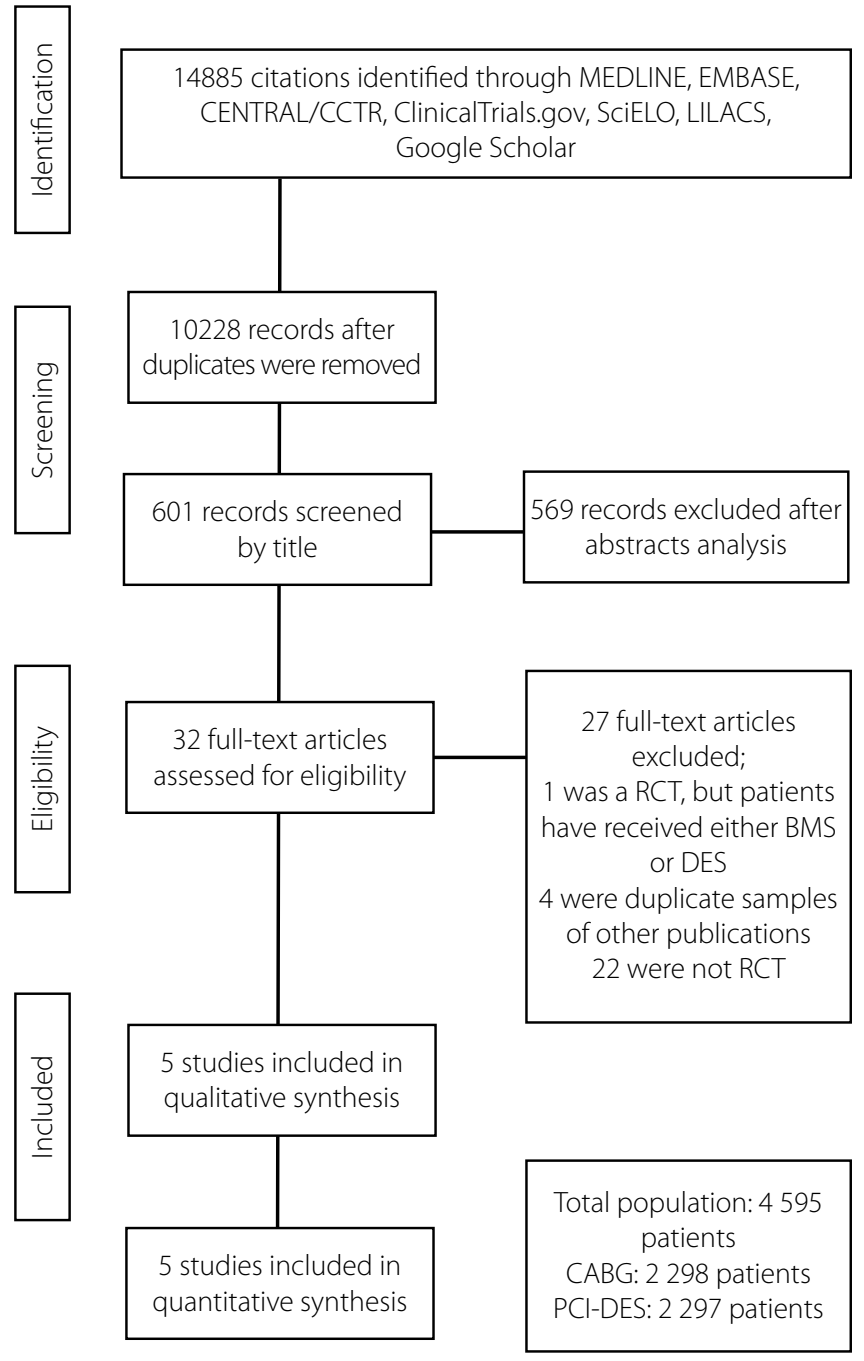

Fig. 1 - Flow diagram of studies included in data search. $B M S=$ bare-metal stents; $C A B G=$ coronary artery bypass grafting; CENTRAL/CCTR=Cochrane Central Register of Controlled Trials; LILACS=Latin American and Caribbean Health Sciences Literature; $P C I-D E S=$ percutaneous coronary intervention/drug-eluting stent; $R C T=$ randomized controlled trial; SCiELO=Scientific Electronic Library Online

\section{Study Characteristics}

Characteristics of each study are shown in Table 1. A total of 4.595 patients were studied, with 2.298 receiving CABG and 2.297 receiving PCI with DES, during the years of 2003 to 2016. Two studies ${ }^{[3,14]}$ mostly used Cypher stent (sirolimus), one $\mathrm{e}^{[4]}$ used Taxus stent (paclitaxel), one $\mathrm{e}^{[5]}$ used Xience stent (everolimus) and one ${ }^{[6]}$ predominantly used Biomatrix Flex stent (biolimus; the latter was the recommended study stent but other "Conformité Européene-marked" DES could be used at the operators' discretion). The overall internal validity was moderate and is illustrated in Table 2. 
Table 1. Study characteristics.

\begin{tabular}{|c|c|c|c|c|c|c|c|c|c|c|c|c|}
\hline 号 & $\stackrel{\underline{n}}{\underline{\Xi}}$ & 蒽 & 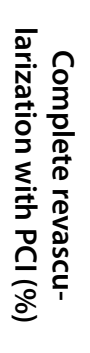 & $\begin{array}{l}\Omega \\
\stackrel{D}{\text { D }} \\
\stackrel{2}{\Xi}\end{array}$ & $\begin{array}{l}\frac{5}{3} \\
\$ \\
0 \\
5 \\
\frac{5}{0} \\
\frac{0}{0}\end{array}$ & 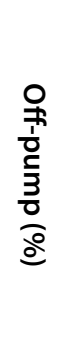 & 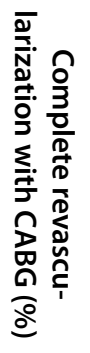 & 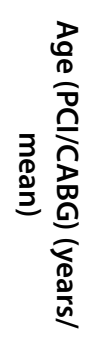 & 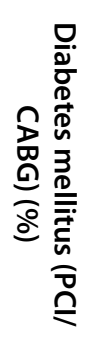 & 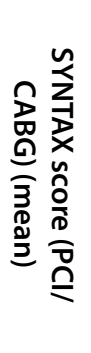 & 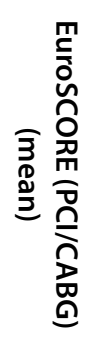 & $\begin{array}{l}\frac{x}{\infty} \\
\stackrel{2}{n}\end{array}$ \\
\hline EXCEL trial[5] & 948 & Xience (100\%) & NR & 957 & 98.8 & 29 & NR & $66 / 66$ & $30 / 28$ & $21 / 21$ & NR & 2010-2016 \\
\hline NOBLE trial[6] & 592 & $\begin{array}{c}\text { Biomatrix Flex } \\
\text { (predominantly) }\end{array}$ & 92 & 592 & 93 & 16 & NR & $66 / 66$ & $15 / 15$ & $23 / 22$ & $2 / 2$ & 2008-2015 \\
\hline PRECOMBAT tria|[3] & 300 & Cypher (100\%) & 68 & 300 & 93.6 & 63.8 & 70 & $62 / 63$ & $34 / 30$ & $24 / 26$ & $2.6 / 2.8$ & 2004-2009 \\
\hline SYNTAX trial[ ${ }^{[4]}$ & 357 & Taxus (100\%) & 65 & 348 & 97 & NR & 73 & $66 / 65$ & $24 / 26$ & $30 / 30$ & $3.9 / 3.9$ & 2005-2007 \\
\hline $\begin{array}{c}\text { Boudriot et al. }{ }^{[14]} \\
2011\end{array}$ & 100 & $\begin{array}{c}\text { Cypher (98\%) } \\
\text { Taxus (2\%) }\end{array}$ & 98 & 101 & 99 & 46 & 97 & $66 / 69$ & $40 / 30$ & $24 / 23$ & $2.4 / 2.6$ & 2003-2009 \\
\hline
\end{tabular}

Biomatrix Flex: Biolimus-eluting stent; Cypher: sirolimus-eluting stent; Taxus: paclitaxel-eluting stent; Xience: everolimus-eluting stent. $C A B G=$ coronary artery bypass grafting; $D E S=$ drug-eluting stent; $L A D=$ eft anterior descending artery; LIMA=left internal mammary artery; $\mathrm{PCl}=$ percutaneous coronary intervention; $\mathrm{NR}=$ non-reported

Table 2. Analysis of risk of bias - internal validity.

\begin{tabular}{l|c|c|c|c|c}
\hline Study & $\begin{array}{c}\text { Selection } \\
\text { bias }\end{array}$ & $\begin{array}{c}\text { Performance } \\
\text { bias }\end{array}$ & Attrition bias & $\begin{array}{c}\text { Detection } \\
\text { bias }\end{array}$ & $\begin{array}{c}\text { Multivariate adjustment } \\
\text { for possible confounders }\end{array}$ \\
\hline EXCEL tria|[5] & A & C & A & A & Probably adequate \\
\hline NOBLE trial[6] & A & C & A & A & Probably adequate \\
\hline PRECOMBAT tria|[3] & A & C & A & A & Probably adequate \\
\hline SYNTAX trial[4] & A & C & A & D & Probably adequate \\
\hline Boudriot et al. ${ }^{[14]} 2011$ & A & C & A & A & Probably adequate \\
\hline
\end{tabular}

This analysis was performed by 2 independent reviewers. The overall bias of the combined studies was considered low.

$A=$ risk of bias is low; $B=$ risk of bias is moderate; $C=$ risk of bias is high; $D=$ unclear to determine

\section{Synthesis of Results}

The RR for death in the CABG group compared with that in the PCI-DES group in each study, at 1-year time point, is reported in Figure 2A. There was evidence of moderate heterogeneity of treatment effect among the studies for death. The overall RR $(95 \% \mathrm{Cl}$ ) of death showed no difference between CABG and PClDES at 1-year (random effect model: RR 0.973, $P=0.830$ ).

The RR for $\mathrm{MI}$ in the CABG group compared with that in the $\mathrm{PCl}$-DES group in each study, at 1-year time point, is reported in Figure 2B. There was evidence of substantial heterogeneity of treatment effect among the studies for MI. The overall RR (95\% $\mathrm{Cl}$ ) for $\mathrm{MI}$ showed no difference between $\mathrm{CABG}$ and PCI-DES at 1-year (random effect model: RR 0.694, $P=0.148$ ).

The RR for stroke in the CABG group compared with that in the $\mathrm{PCI}$-DES group in each study, at 1-year time point, is reported in Figure 2C. There was evidence of substantial heterogeneity of treatment effect among the studies for stroke. The overall RR $(95 \% \mathrm{Cl}$ ) for stroke showed no difference between CABG and PClDES at 1-year (random effect model: RR 1.224, $P=0.598$ ).
The RR for TVR in the CABG group compared with that in the PClDES group in each study, at 1-year time point, is reported in Figure 2D. There was no evidence of heterogeneity of treatment effect among the studies for TVR. The overall RR (95\% Cl) for TVR showed a statistically significant difference between CABG and PCI-DES at 1-year, favoring CABG (random effect model: RR 0.583, $P<0.001$ ).

The RR for MACCE in the CABG group compared with that in the PCI-DES group in each study, at 1-year time point, is reported in Figure 2E. There was evidence of substantial heterogeneity of treatment effect among the studies for MACCE. The overall RR (95\% Cl) for MACCE showed no difference between CABG and PCI-DES at 1-year (random effect model: RR 0.948, $P=0.680$ ).

\section{Risk of Bias Across Studies}

Funnel plot analysis (Figure 3) disclosed no asymmetry around the axis for the treatment effect when the outcomes were analyzed, which means we probably have no publication bias related to these outcomes. 
A

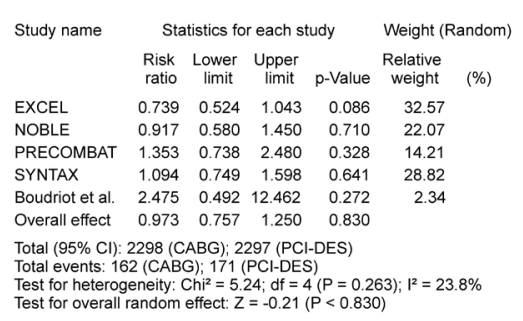

Test for overall random effect: $Z=-0.21(P<0.830)$

\begin{tabular}{|c|c|c|c|c|c|}
\hline \multirow[t]{2}{*}{ Study name } & \multicolumn{4}{|c|}{ Statistics for each study } & Weight (Random) \\
\hline & $\begin{array}{l}\text { Risk } \\
\text { ratio }\end{array}$ & $\begin{array}{c}\text { Lower } \\
\text { limit }\end{array}$ & $\begin{array}{c}\text { Upper } \\
\text { limit }\end{array}$ & p-Value & $\begin{array}{l}\text { Relative } \\
\text { weight (\%) }\end{array}$ \\
\hline EXCEL & 1.059 & 0.778 & 1.442 & 0.714 & 33.68 \\
\hline NOBLE & 0.345 & 0.170 & 0.701 & 0.003 & 21.55 \\
\hline PRECOMBAT & 0.833 & 0.257 & 2.701 & 0.761 & 12.14 \\
\hline SYNTAX & 0.586 & 0.323 & 1.064 & 0.079 & 24.79 \\
\hline Boudriot et al. & 0.990 & 0.205 & 4.789 & 0.990 & 7.85 \\
\hline Overall effect & 0.694 & 0.423 & 1.138 & 0.148 & \\
\hline
\end{tabular}

c

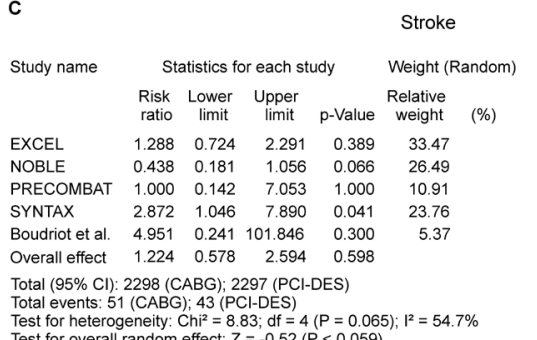

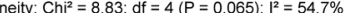
Test for overall random effect: $Z=-0.52(P<0.059)$
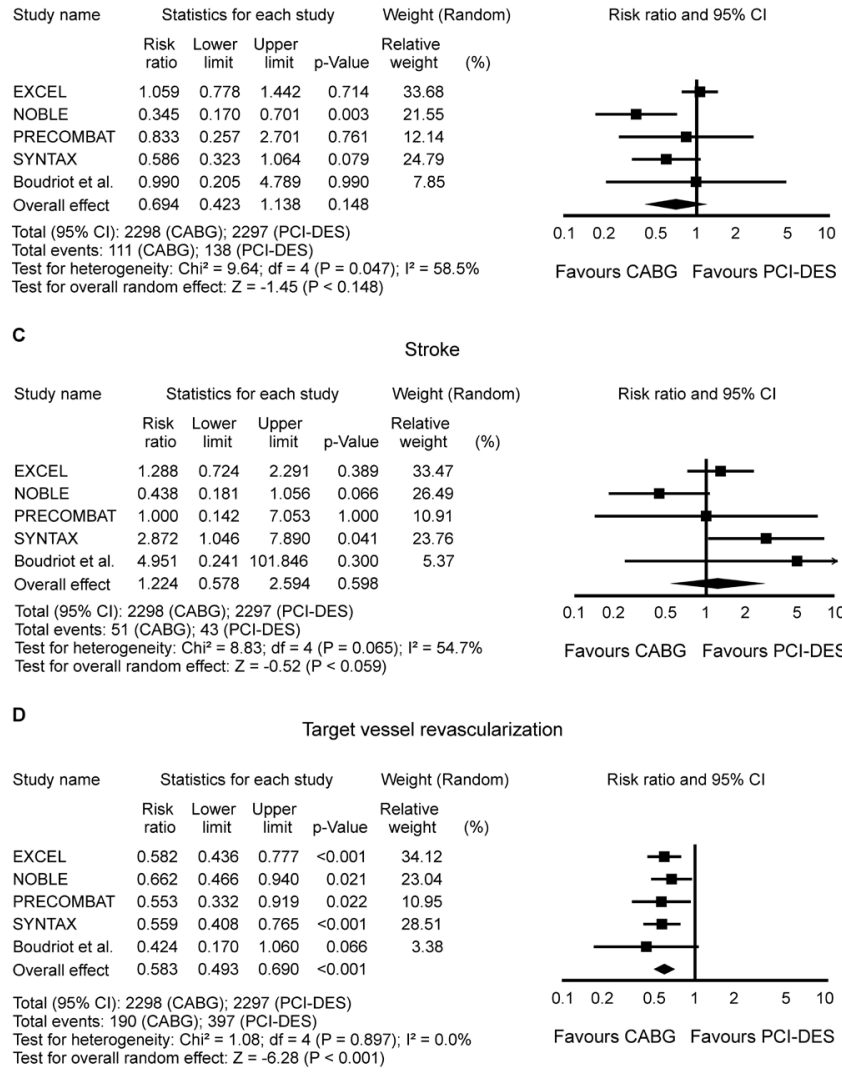

Favours CABG Favours PCI-DES

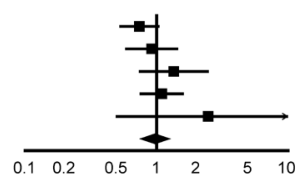

Favours CABG Favours PCI-DES

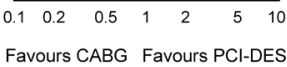

Risk ratio and $95 \% \mathrm{Cl}$

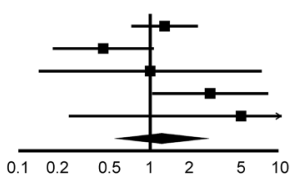

Favours CABG Favours PCI-DES
Risk ratio and $95 \% \mathrm{Cl}$

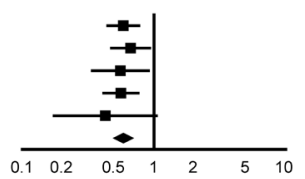

Favours CABG Favours PCI-DES
E

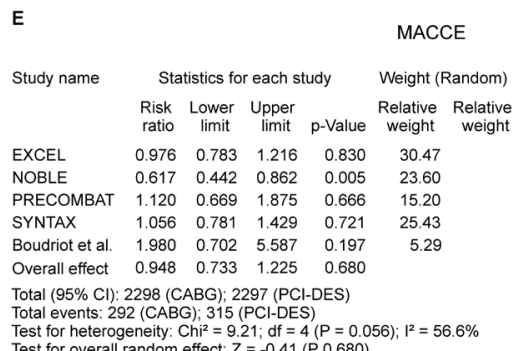

Total for heterogeneity: $\mathrm{Ch}^{2}=9.21 ; \mathrm{df}=4(\mathrm{P}=0.056) \mathrm{I}^{2}=56.6 \%$ Test for overall random effect: $Z=-0.41$ ( $P$ O 0.680 )

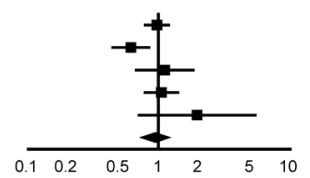

Favours CABG Favours PCI-DES

Fig. 2 - Risk ratio (RR) and conclusions plot of death, myocardial infarction (MI), stroke, target vessel revascularization (TVR), and major adverse cerebrovascular and cardiovascular events (MACCE) associated with coronary artery bypass grafting (CABG) vs. percutaneous coronary intervention/drug-eluting stent (PCI-DES). $\mathrm{Cl}=$ Confidence interval

\section{Sensitivity Analysis}

Sensitivity analyses performed by removing each single study from the meta-analysis to determine the influence of an individual data set to the pooled RR showed that the EXCEL trial caused a major change in direction/magnitude of statistical findings regarding the outcome $\mathrm{Ml}$ (Figure 4B). When this study was removed from the analysis, a statistically significant difference in favor of CABG appeared, which means that this study actually had an excessive influence on the overall results concerning the outcome Ml, favoring excessively the PCI-DES when it was included.

\section{Meta-regression Analysis}

Meta-regression coefficients were not statistically significant for age, diabetes, smoke, hypertension, SYNTAX score or distal left main lesion, which means that none of these evaluated factors had any modulation influence on the final effect, regarding death, MI, stroke, TVR or MACCE. When we analyzed the outcome "MI" and the pre-determined factor "female gender", it was observed a statistically significant coefficient for proportion of female patients and RR for MI (coefficient -0.42 ; 95\% Cl -0.73 to $0.11 ; P=0.007$; Figure 5 ). We can observe that the greater the proportion of female patients, the lower the RR for $\mathrm{MI}$ in the group CABG in comparison to PCI-DES group.

\section{DISCUSSION}

\section{Summary of Evidence}

The results of this meta-analysis demonstrate that $\mathrm{PCI}$ with DES for ULMCA disease presents a significantly higher risk for TVR at 1-year follow-up in comparison to CABG, being this outcome under no influence of statistical heterogeneity or publication bias. Although there was no difference in the risk for death, MI, stroke and MACCE, these summary measures were underpowered by heterogeneity of the effects.

We've also observed that the EXCEL trial had had a major influence on the overall results regarding the outcome $\mathrm{Ml}$, favoring excessively the group PCI-DES. Interestingly, as evidenced by the meta-regression analysis, the gender seems to play a certain role in the results, since we've detected that when there were more women in the group $C A B G$, more beneficial was this strategy in comparison to $\mathrm{PCI}$ with-DES.

\section{Considerations}

The length of follow-up considered for this study may have been too short (1 year) to truly detect differences between the treatment groups. CABG is associated with a higher early mortality rate from perioperative complications, and it is possible that with a longer follow-up, CABG patients may have an improved survival rate compared to patients undergoing $\mathrm{PCI}$ with DES. Curiously, we've observed no statistically significant difference regarding the outcome stroke, although we had expected a higher risk in the $C A B G$ group. The long-term durability of $\mathrm{PCl}$ vs. CABG remains undetermined and will require studies with longer follow-ups to produce a robust meta-analysis of long- 


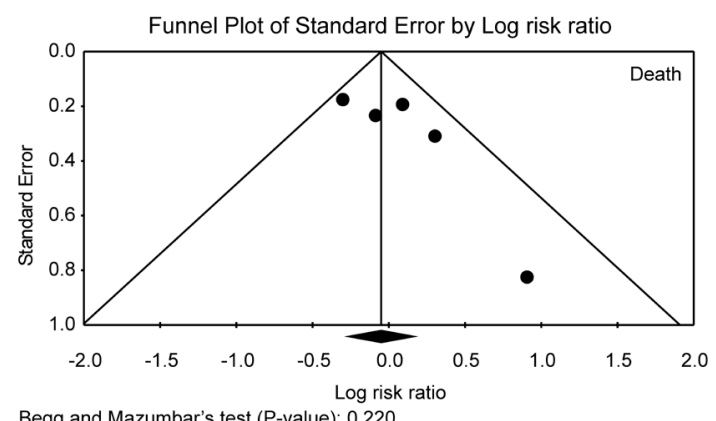

Begg and Mazumbar's test (P-value): 0.220

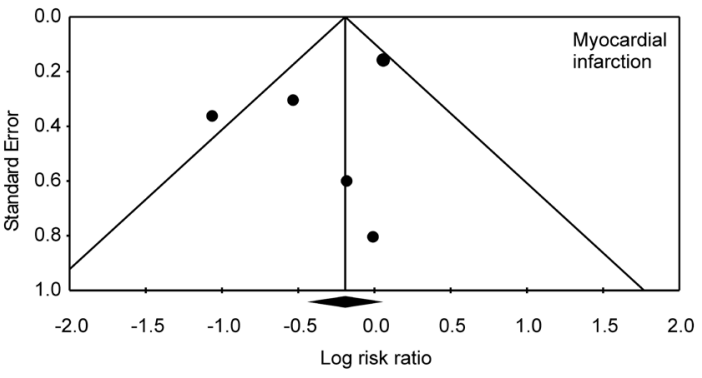

Begg and Mazumbar's test (P-value): 0.500

Egger's test (P-value): 0.405

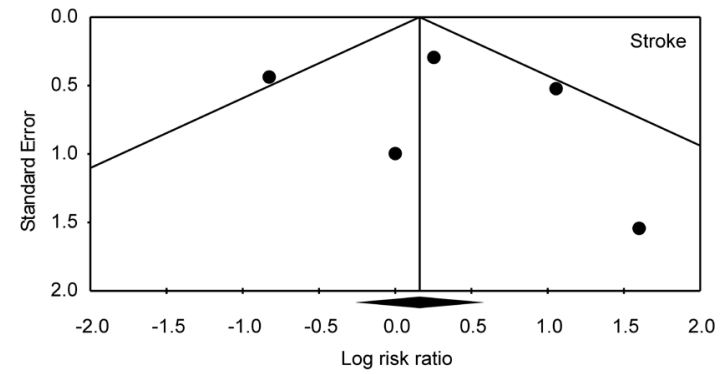

Begg and Mazumbar's test (P-value): 0.806

Egger's test (P-value): 0.743

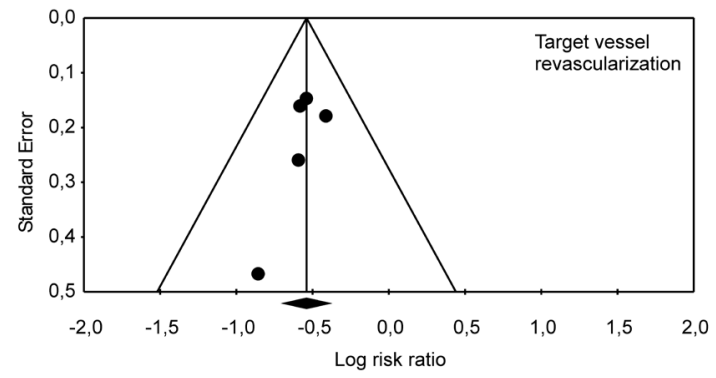

Begg and Mazumbar's test (P-value): 0.462

Egger's test (P-value): 0.291

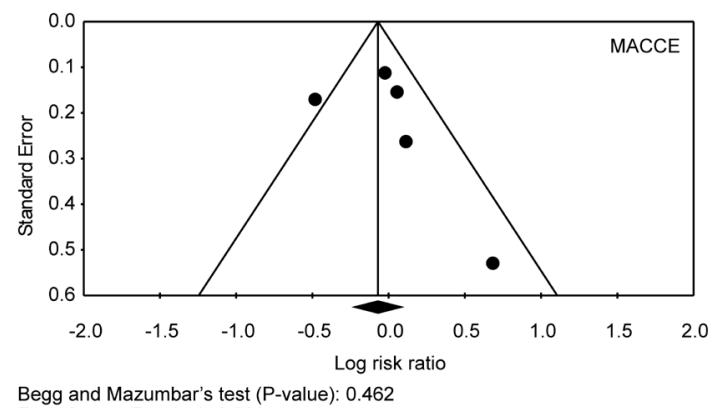

Begg and Mazumbar's test (P-value): 0.462

Egger's test (P-value): 0.583

Fig. 3 - Publication bias analysis by funnel plot graphic. MACCE $=$ Major adverse cerebrovascular and cardiovascular events

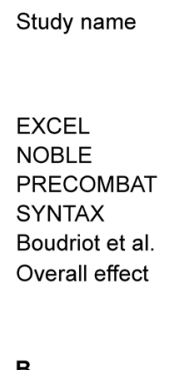

Death
Statistics with study removed

$$
\text { Lower Upper }
$$

Point limit limit $p$-Value

$\begin{array}{lllll}1.098 & 0.847 & 1.423 & 0.481\end{array}$

$\begin{array}{llll}1.019 & 0.721 & 1.440 & 0.915\end{array}$

$\begin{array}{llll}0.919 & 0.708 & 1.191 & 0.522\end{array}$

$\begin{array}{llll}0.949 & 0.678 & 1.329 & 0.762\end{array}$

$\begin{array}{llll}0.948 & 0.744 & 1.208 & 0.667\end{array}$

$\begin{array}{llll}0.973 & 0.757 & 1.250 & 0.830\end{array}$

Study name

Statistics with study removed

Lower Upper

Point limit limit $p$-Value

$\begin{array}{lllll}\text { EXCEL } & 0.531 & 0.352 & 0.800 & 0.003\end{array}$

NOBLE

PRECOMBAT

SYNTAX

Boudriot et al

Overall effect

$\begin{array}{lllll}0.928 & 0.710 & 1.213 & 0.586\end{array}$

$\begin{array}{llll}0.670 & 0.375 & 1.199 & 0.178\end{array}$

$\begin{array}{lllll}0.725 & 0.375 & 1.402 & 0.339\end{array}$

$\begin{array}{llll}0.668 & 0.383 & 1.163 & 0.154\end{array}$

$\begin{array}{llll}0.694 & 0.423 & 1.138 & 0.148\end{array}$

C

Study name

Statistics with study removed

Lower Upper

Point limit limit $p$-Value

EXCEL

NOBLE

PRECOMBAT

SYNTAX

Boudriot et al.

Overall effect

D

Study name
EXCEL
NOBLE
PRECOMBAT
SYNTAX
Boudriot et al.
Overall effect
E

Study name

Statistics with study removed

Point limit limit

$\begin{array}{lllll}\text { EXCEL } & 0.965 & 0.652 & 1.429 & 0.859\end{array}$

$\begin{array}{lllll}\text { NOBLE } & 1.033 & 0.875 & 1.219 & 0.705\end{array}$

$\begin{array}{lllll}\text { PRECOMBAT } & 0.924 & 0.683 & 1.251 & 0.609\end{array}$

$\begin{array}{lllll}\text { SYNTAX } & 0.930 & 0.655 & 1.319 & 0.683\end{array}$

$\begin{array}{lllll}\text { Boudriot et al. } \quad 0.909 & 0.709 & 1.166 & 0.453\end{array}$

Overall effect

$\begin{array}{llll}0.948 & 0.733 & 1.225 & 0.680\end{array}$
Risk ratio $(95 \% \mathrm{Cl})$

with study removed

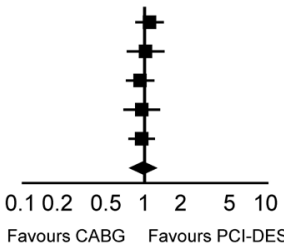

Favours CABG Favours PCI-DES

Risk ratio $(95 \% \mathrm{Cl})$

with study removed

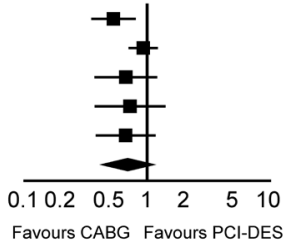

Risk ratio $(95 \% \mathrm{Cl})$

with study removed

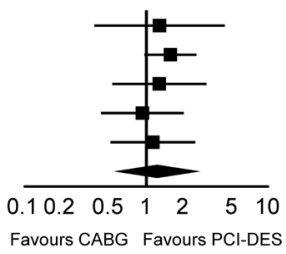

Favours CABG Favours PCI-DES

Risk ratio $(95 \% \mathrm{Cl})$

with study removed

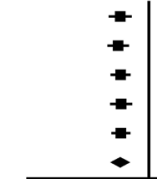

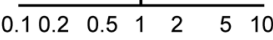

Favours CABG Favours PCI-DES

Risk ratio $(95 \% \mathrm{Cl})$

with study removed

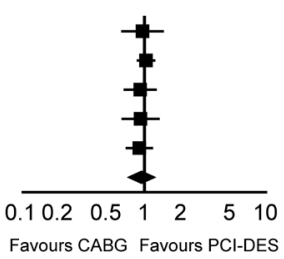

Fig. 4 - Sensitivity analyses (one study removed).

$C A B G=$ coronary artery bypass grafting; $C l=$ confidence interval; $M A C C E=$ major adverse cerebrovascular and cardiovascular events; PCI-DES=percutaneous coronary intervention/drug-eluting stent 
Regression of Female (\%) on Log risk ratio for Myocardial infarction

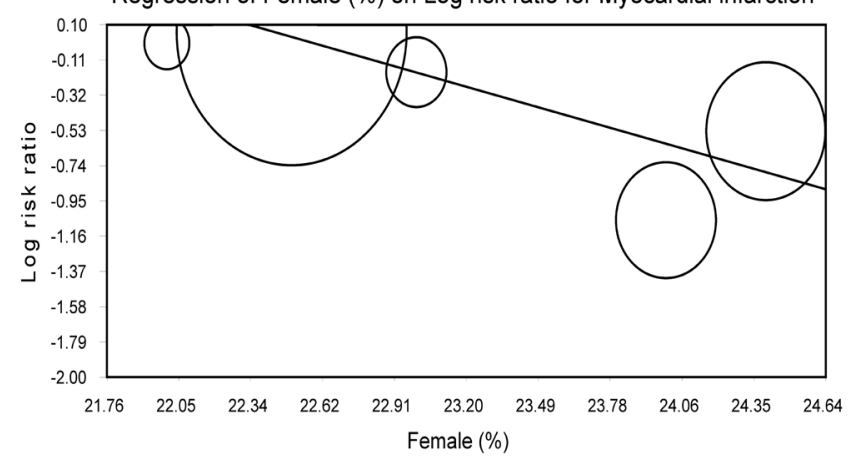

Coefficient $=-0.42(95 \% \mathrm{Cl}-0.73$ to 0.11$), \mathrm{SE}=0.15$

$Z=-2.69(P$-value $=0.007)$

Fig. 5 - Meta-regression analysis.

$\mathrm{Cl}=$ confidence interval; SE=standard error

term results. Up to now, only SYNTAX, PRECOMBAT and NOBLE trials published their 5 -year follow-ups.

Regarding the major influence on the overall rate of Ml exerted by the EXCEL trial, favoring excessively the group PCI-DES, we must bear in mind that this study excluded patients with SYNTAX score $\geq 33$. On the other hand, the NOBLE trial has enrolled patients with ostium, mid-shaft and/or bifurcation and with no more than three additional non-complex PCI lesions, defined as length $<25$ $\mathrm{mm}$, non-chronic total occlusion, non-two-stent bifurcation, noncalcified and non-tortuous coronary lesions.

The gender seemed to play a certain role in the results. Intriguingly, there are studies showing that women experience higher short-term and long-term mortality rates after $\mathrm{PCl}$ compared to men ${ }^{[15]}$ and showing that women have worse longterm outcomes after CABG than men ${ }^{[16]}$. To sum up, women tend to benefit less from both invasive strategies. Nevertheless, when it comes to comparing CABG with PCI-DES, it seems that the former presents better results, since studies showed that CABG may provide the greatest benefit to patients who have most extensive heart disease $e^{[17,18]}$, maybe because women (compared with men) are, on average, older and more likely to have diabetes and hypertension and to present for surgery with urgent/ emergent status ${ }^{[16]}$.

One of the limitations is the heterogeneity of the strategies across the studies. Among PCl strategies, some studies used either only sirolimus-stent or only paclitaxel-stents or predominantly biolimus-stents or only everolimus-stents, and some mixed drugeluting stents, etc. Campos et al. ${ }^{[19]}$ underlined some differences about how the Heart Team assessed the ULMCA as being significant in the studies. For example, the NOBLE trial adopted as significant an ULMCA with a visually assessed DS $>50 \%$ or a fractional flow reserve (FFR) $<0.80$. The EXCEL trial defined significant ULMCA as one of the following: $\mathrm{DS} \geq 70 \%$ (visually estimated) or $\mathrm{DS} \geq 50 \%$ but $<70 \%$ (requiring non-invasive or invasive [FFR $\leq 0.80$ ] evidence of ischaemia or intravascular ultrasound minimal lumen area [IVUS MLA] $\leq 6.0 \mathrm{~mm}^{2}$ ). Additionally, the EXCEL trial has enrolled patients with a left main equivalent disease, defined as bifurcation disease, with both the ostial left anterior descending (LAD) artery and ostial left circumflex artery (LCX) stenoses having $\geq 70 \%$ DS. If one or both ostial LAD and ostial LCX stenoses are $\geq 50 \%$ and $<70 \%$ stenotic by visual estimation, then this(ese) lesion(s) is(are) demonstrated to be significant either by non-invasive or invasive (FFR $\leq 0.80$ ) evidence of ischaemia in its myocardial distribution or IVUS MLA $\leq 4.0 \mathrm{~mm}^{2}$. By protocol, in EXCEL, FFR was the preferred strategy to stratify lesion significance. Among CABG strategies, there is variability in rates of use of internal thoracic artery, use of cardiopulmonary bypass (on-pump vs. off-pump CABG), etc. And between both strategies, an important aspect to consider is the rate of complete revascularization (that was not reported adequately in 2 studies ${ }^{[5,6]}$, but in the 2 studies $^{[3,4]}$ that reported these rates, both arms presented high rates of incomplete revascularization, reaching around $30 \%$ ), which reflects in the outcomes.

Curiously, the publication of EXCEL and NOBLE trials, both studying the same issue and emerging with different results, may have confused some cardiologists and cardiovascular surgeons. In the EXCEL study, investigators randomized 948 patients with ULMCA disease to $P C I$ with Xience and 957 patients to CABG surgery. The primary endpoint-a composite that included allcause mortality, stroke, or MI at 3 years-occurred in 15.4\% of patients treated with $\mathrm{PCl}$ and $14.7 \%$ of patients treated with CABG $(P=0.02$ for non-inferiority). The researchers also analyzed data at the $30^{\text {th }}$ day, a secondary endpoint. The rate of death, stroke or MI was significantly higher among the CABG-treated patients (4.9\% vs. $7.9 \%$; HR $0.61 ; 95 \% \mathrm{Cl} 0.42-0.88$ ), and this difference was driven by a considerably increased risk of MI (3.9\% vs. 6.2\%; HR 0.63; 95\% Cl 0.42-0.95). In particular, there was a significantly increased risk of "large" periprocedural MI with CABG, which was defined as CK-MB more than 10 times the upper limit of normal (or 5 times the upper limit of normal plus other evidence of MI). In the NOBLE trial, 1,201 patients with ULMCA disease were randomized to $\mathrm{PCl}$ or $\mathrm{CABG}$. The 5-year estimate of MACCE-a composite of all-cause mortality, nonprocedural $\mathrm{Ml}$, any repeat coronary revascularization, and stroke-occurred in $29 \%$ of patients treated with $\mathrm{PCl}$ and 19\% of patients who underwent $C A B G$, a difference that exceeded the limit for non-inferiority ( $P=0.007$ for superiority). Therefore, the results of these studies are clearly conflicting.

There are inherent limitations in meta-analyses, including the use of cumulative data from summary estimates. Patients' data were gathered from published data, not from individual patient follow-up. Access to individual patient's data would have enabled us to conduct further subgroup analysis and propensity analysis to account for differences between the treatment groups. This metaanalysis included only data from randomized studies, which do not reflect the "real world" but, on the other hand, are less limited by publication bias, treatment bias, confounders, and a certain tendency to overestimate the treatment effects observed in observational studies, since patients'selection alters the outcomes and thus makes non-randomized studies less robust.

A final limitation is the absence of adequate published comparative data for the third therapeutic option, medical therapy. PCI with DES has not been compared yet with medical therapy alone when we consider ULMCA disease, but CABG has been shown to be superior to medical therapy in this set. 


\section{CONCLUSION}

We found evidence that argues against the so-called "noninferiority" of PCI with DES in comparison to CABG surgery and against the idea that $\mathrm{PCl}$ can be considered a reasonable choice in elective cases (not mentioning prohibitive risk patients, acute patients, and those who reject surgery). Given that, although the rates of death, MI, stroke, and MACCE between both strategies were not statistically different (remembering the heterogeneity related to these outcomes), the need of new procedures were clearly lower in patients treated with CABG surgery. However, careful analysis of the data shows that no definite conclusion can be drawn from the evidence available due to the heterogeneity of studies regarding the outcomes, heterogeneity of strategies (different drug-eluting stents, different ways to perform surgery, etc), and heterogeneity of coronary lesions complexity.

Needless to say, we are living in a changing world. It is incredible how fast the winds of change blow through the medical literature. Nowadays, an author publishes a metaanalysis boldly recommending changing the level of evidence of PCI-DES in ULMCA patients in the Journal of the American College of Cardiology (JACC), a high-quality journal, and then, after new evidence came out, the same author changes his/her stance on this issue one more time. New data will come when we have the 5-year results of these trials, when the scientific community will be enlightened with stronger and definitive results. Disagreeing with other authors, we conclude that "based on our study, revision of the guidelines regarding left main $\mathrm{PCl}$ with DES must be viewed with caution, and we still do not have enough evidence that makes the level of evidence of current recommendations raises from $B$ to $A^{\prime \prime}$.

\section{Authors' roles $\&$ responsibilities}

MPBOS Conception and study design; data management; manuscript redaction or critical review of its content; final manuscript approval

AFS Substantial contributions to the conception or design of the work; or the acquisition, analysis, or interpretation of data for the work; final manuscript approval

RGAM Substantial contributions to the conception or design of the work; or the acquisition, analysis, or interpretation of data for the work; final manuscript approval

MLA Substantial contributions to the conception or design of the work; or the acquisition, analysis, or interpretation of data for the work; final manuscript approval

AMM Conception and study design; data management; manuscript redaction or critical review of its content; final manuscript approval

FPVS Conception and study design; data management; manuscript redaction or critical review of its content; final manuscript approval

RCL Conception and study design; data management; manuscript redaction or critical review of its content; final manuscript approval

\section{REFERENCES}

1. Windecker S, Kolh P, Alfonso F, Collet JP, Cremer J, Falk V, et al. 2014 ESC/EACTS Guidelines on myocardial revascularization: the task force on myocardial revascularization of the European Society of Cardiology (ESC) and the European Association for Cardio-Thoracic Surgery (EACTS) Developed with the special contribution of the European Association of Percutaneous Cardiovascular Interventions (EAPCI). Eur Heart J. 2014;35(37):2541-619.

2. Capodanno D, Stone GW, Morice MC, Bass TA, Tamburino C. Percutaneous coronary intervention versus coronary artery bypass graft surgery in left main coronary artery disease. A meta-analysis of randomized clinical data. J Am Coll Cardiol. 2011;58(14):1426-32.

3. Park SJ, Kim YH, Park DW, Yun SC, Ahn JM, Song HG, et al. Randomized trial of stents versus bypass surgery for left main coronary artery disease. N Engl J Med. 2011;364(18):1718-27.

4. Serruys PW, Morice MC, Kappetein AP, Colombo A, Holmes DR, Mack MJ, et al; SYNTAX Investigators. Percutaneous coronary intervention versus coronary-artery bypass grafting for severe coronary artery disease. N Engl J Med. 2009;360(10):961-72.

5. Stone GW, Sabik JF, Serruys PW, Simonton CA, Généreux P, Puskas J, et al; EXCEL Trial Investigators. Everolimus-eluting stents or bypass surgery for left main coronary artery disease. N Engl J Med. 2016;375(23):2223-35.

6. Mäkikallio T, Holm NR, Lindsay M, Spence MS, Erglis A, Menown IB, et al; NOBLE study investigators. Percutaneous coronary angioplasty versus coronary artery bypass grafting in treatment of unprotected left main stenosis (NOBLE): a prospective, randomised, open-label, non-inferiority trial. Lancet. 2016;388(10061):2743-52.

7. Moher D, Liberati A, Tetzlaff J, Altman DG; PRISMA Group. Preferred reporting items for systematic reviews and meta-analyses: the PRISMA statement. Ann Intern Med. 2009;151(4):264-9.

8. Higgins J, Altman DG. Assessing risk of bias in included studies. In: Higgins J, Green S, eds. Cochrane handbook for systematic reviews of interventions. Version 5.0. The Cochrane Collaboration; 2008.

9. Higgins JP,Thompson SG, Deeks JJ, Altman DG. Measuring inconsistency in meta-analyses. BMJ. 2003;327(7414):557-60.

10. DerSimonian R, Kacker R. Random-effects model for meta-analysis of clinical trials: an update. Contemp Clin Trials. 2007;28(2):105-14.

11. Begg CB, Mazumdar M. Operating characteristics of a rank correlation test for publication bias. Biometrics. 1994;50(4):1088-101.

12. Egger M, Davey Smith G, Schneider M, Minder C. Bias in meta-analysis detected by a simple, graphical test. BMJ. 1997;315(7109):629-34.

13. Hozo SP, Djulbegovic B, Hozo I. Estimating the mean and variance from the median, range, and the size of a sample. BMC Med Res Methodol. 2005;5:13.

14. Boudriot E, Thiele H, Walther T, Liebetrau C, Boeckstegers P, Pohl T, et al. Randomized comparison of percutaneous coronary intervention with sirolimus-eluting stents versus coronary artery bypass grafting in unprotected left main stem stenosis. J Am Coll Cardiol. 2011;57(5):538-45.

15. Singh M, Rihal CS, Gersh BJ, RogerVL, Bell MR, Lennon RJ, et al. Mortality differences between men and women after percutaneous coronary interventions: 12-year, single-center experience. J Am Coll Cardiol. 2008;51(24):2313-20.

16. Hassan A, Chiasson M, Buth K, Hirsch G. Women have worse longterm outcomes after coronary artery bypass grafting than men. Can J Cardiol. 2005;21(9):757-62.

17. Yusuf S, Zucker D, Passamani E, Peduzzi P, Takaro T, Fisher LD, et al. Effect of coronary artery bypass graft surgery on survival: overview of 10-year results from randomised trials by the Coronary Artery Bypass Graft Surgery Trialists Collaboration. Lancet. 1994;344(8922):563-70.

18. Muhlbaier LH, Pryor DB, Rankin JS, Smith LR, Mark DB, Jones RH, et al. 
Observational comparison of event-free survival with medical and surgical therapy in patients with coronary artery disease: 20 years of follow-up. Circulation. 1992;86(5 Suppl.):II198-204.
19. Campos CM, Christiansen EH, Stone GW, Serruys PW. The EXCEL and NOBLE trials: similarities, contrasts and future perspectives for left main revascularisation. Eurolntervention. 2015;11(Suppl V):V115-9. 